\title{
Experimental Nondestructive Test for Estimation of Buckling Load on Unstiffened Cylindrical Shells Using Vibration Correlation Technique
}

\author{
Kaspars Kalnins, ${ }^{1}$ Mariano A. Arbelo, ${ }^{2}$ Olgerts Ozolins, ${ }^{1}$ Eduards Skukis, ${ }^{1}$ \\ Saullo G. P. Castro, ${ }^{3}$ and Richard Degenhardt ${ }^{4}$ \\ ${ }^{1}$ Riga Technical University (RTU), Institute of Materials and Structures, Azenes 16, Riga LV-1048, Latvia \\ ${ }^{2}$ Department of Aeronautics, Aeronautics Institute of Technology (ITA), 12228-900 São José dos Campos, SP, Brazil \\ ${ }^{3}$ Embraer (Brazilian Aerospace Company), 12227-901 São José dos Campos, SP, Brazil \\ ${ }^{4}$ DLR, Institute of Composite Structures and Adaptive Systems, Lilienthalplatz 7, 38108 Braunschweig, Germany \\ Correspondence should be addressed to Mariano A. Arbelo; arbelom@gmail.com
}

Received 4 June 2015; Accepted 27 July 2015

Academic Editor: Matteo Aureli

Copyright (c) 2015 Kaspars Kalnins et al. This is an open access article distributed under the Creative Commons Attribution License, which permits unrestricted use, distribution, and reproduction in any medium, provided the original work is properly cited.

\begin{abstract}
Nondestructive methods, to calculate the buckling load of imperfection sensitive thin-walled structures, such as large-scale aerospace structures, are one of the most important techniques for the evaluation of new structures and validation of numerical models. The vibration correlation technique (VCT) allows determining the buckling load for several types of structures without reaching the instability point, but this technique is still under development for thin-walled plates and shells. This paper presents and discusses an experimental verification of a novel approach using vibration correlation technique for the prediction of realistic buckling loads of unstiffened cylindrical shells loaded under axial compression. Four different test structures were manufactured and loaded up to buckling: two composite laminated cylindrical shells and two stainless steel cylinders. In order to characterize a relationship with the applied load, the first natural frequency of vibration and mode shape is measured during testing using a 3D laser scanner. The proposed vibration correlation technique allows one to predict the experimental buckling load with a very good approximation without actually reaching the instability point. Additional experimental tests and numerical models are currently under development to further validate the proposed approach for composite and metallic conical structures.
\end{abstract}

\section{Introduction}

Southwell [1] proposed one of the first nondestructive methods to predict the buckling load of simple structures such as slender beams, which was modified by Galletly and Reynolds [2] in order to be applicable for stiffened cylindrical shells. The main disadvantage of the latter is the need of high applied loads, close to the onset of buckling, in order to provide a reliable prediction of the buckling load.

Vibration correlation methods can also be used as a nondestructive technique. The concept of relating vibration characteristics to buckling loads was considered at the beginning of the 20th century for Sommerfeld, 1905 [3], but only in the 50s some experimental investigations were conducted by Chu, 1949 [4], Lurie, 1952 [5], and Meier, 1953 [6], among others. A very detailed review of the theory, application, experimental setup, and results of the vibration correlation technique (VCT) approach on different structures can be found in the work of Singer et al. [7] (Chapter 15).

For a better understanding of the applications of VCT on plates and shells it is important to classify the method according to its purpose: (1) determination of actual boundary conditions for numerical calculation purposes; (2) direct estimation of buckling load. This paper deals with the direct determination of the buckling load on cylindrical shells.

There is no established procedure about how to apply the VCT for unstiffened cylindrical shells, commonly used in space applications for launcher structures. This type of structure is usually associated with a high imperfection sensitivity, requiring the application of empirical guidelines in order 
TABLE 1: Geometric parameters for tested cylinders.

\begin{tabular}{lccc}
\hline & R15 & Z37 & SST-1 \\
\hline Free length $(L)[\mathrm{mm}]$ & 500 & 800 & 500 \\
Radius $(R)[\mathrm{mm}]$ & 250 & 400 & 250 \\
Thickness $(t)[\mathrm{mm}]$ & 0.523 & 0.785 & 400 \\
Layup [in-out $]$ & {$\left[\left( \pm 24^{\circ}\right) /\left( \pm 41^{\circ}\right)\right] \pm 1^{\circ}$} & {$\left[\left( \pm 34^{\circ}\right) / 0_{2} /\left( \pm 53^{\circ}\right)\right] \pm 1^{\circ}$} & 0.5 \\
\hline
\end{tabular}

to calculate the design buckling load, currently leading to conservative estimations (Degenhardt et al., 2010 [8]). Skukis et al., 2013 [9], presented a preliminary assessment correlating the vibration modes with the buckling load of stainless steel cylinders. If a relationship between the buckling load and the variation of the natural frequencies of vibration exists, it is possible to use the VCT as a nondestructive technique for estimating the real knockdown factor of space structures. Moreover, for this type of structures, there is a remarkable influence of the boundary conditions on the buckling load (see Zimmermann, 1996 [10], and Hühne et al., 2002 [11]), where the VCT could be used for a better characterization of the actual boundary conditions in order to provide reliable data for numerical simulation, such as finite element models (see Hilburger et al., 2004 [12], Degenhardt et al., 2008 [13], and Degenhardt et al., 2010 [8]).

Recent efforts to improve the work done so far on the VCT field are presented by Jansen et al., 2014 [14], where new semianalytical tools are introduced to extend the existing semiempirical VCT for shells, considering both the nonlinear effect of the static state and the nonlinear effect of the geometric imperfections.

The current paper will present and discuss an experimental verification of a new VCT approach presented by Arbelo et al., 2014 [15]. This approach is based on the observations made by Souza et al., 1983 [16]. The original approach proposed by Souza is a linear fit between $(1-p)^{2}$ and $\left(1-f^{4}\right)$, where $p=\left(P / P_{\mathrm{cr}}\right)$ and $f=\left(f_{m} / f_{0}\right) ; P$ is the applied axial load, $P_{\text {cr }}$ is the critical buckling load for a perfect shell, $f_{m}$ is the measured frequency at $P$ load, and $f_{0}$ is the natural frequency of the unloaded shell. Souza states that the value of $(1-p)^{2}$ corresponding to $\left(1-f^{4}\right)=1$ would represent the square of the drop of the load carrying capacity $\left(\xi^{2}\right)$, due to the initial imperfections. However, if this approach is applied to unstiffened cylindrical shells, the results will be negative values of the drop of the load carrying capacity $\left(\xi^{2}\right)$, which does not have a coherent physical meaning (see Arbelo et al., 2014 [15]).

Instead of plotting $(1-p)^{2}$ versus $\left(1-f^{4}\right)$, Arbelo proposed to plot $(1-p)^{2}$ versus $\left(1-f^{2}\right)$ and represented the points by a second-order fitting curve. Therefore, the minimum value of $(1-p)^{2}$ obtained using this approximation represents the square of the knockdown of the load carrying capacity $\left(\xi^{2}\right)$ for unstiffened cylindrical shells. Then, the buckling load can be estimate by

$$
P_{\text {imperfect }}=P_{\mathrm{cr}}\left(1-\sqrt{\xi^{2}}\right) \text {. }
$$

For the validation of the proposed empirical VCT approach, this paper presents four experimental tests conducted on composite and metallic unstiffened cylinders with clamped boundary conditions. The applied load and the first natural frequency of vibration and mode shape are measured and correlated. The initial geometric imperfection shape of each cylinder is measured using a $3 \mathrm{D}$ noncontact laser scan.

The main goal on this work is to compare the predicted buckling load versus the real buckling load measured on samples with different materials, geometries (radius, thickness, and height) and fabrication technologies. More details about each study case are given in the following section.

\section{Experimental Test: Materials and Methods}

2.1. Test Specimen: Overview. Two laminated composites and two stainless steel cylindrical shells are fabricated and tested. Details of each specimen are described in the following.

2.1.1. Composite Cylindrical Shell "R15" with $R / t=478$. The R15 cylinder is fabricated at RTU by hand-layup, using 4 plies of unidirectional (UD) carbon fiber prepreg Hexcel IM7/8552, and cured out of autoclave. The geometry and layup are presented in Table 1 . The material properties were measured according to the ASTM D3039 [17], D3410 [18], and D3518 [19] standards for tension, compression, and shear, respectively. The results are presented in Table 2 , where $E_{i}^{j}$ is the elastic modulus along the fiber direction $(i=1)$ or matrix direction $(i=2)$ in tension $(j=T)$ or compression $(j=C)$. $G_{12}$ is the shear modulus and $v_{12}$ is the Poisson ratio. $S_{i}^{j}$ is the maximum strength along the fiber direction $(i=1)$ or matrix direction $(i=2)$ in tension $(j=T)$ or compression $(j=C)$. $S_{12}$ is the shear strength. $t$-ply is the ply thickness.

After fabrication the top and bottom edges are trimmed and clamped using a resin potting and metallic rings. The final radius over thickness $(R / t)$ ratio is about 478 .

2.1.2. Composite Cylindrical Shell "Z37” with $R / t=510$. The Z37 cylinder is fabricated at DLR-Braunschweig by handlayup, using 6 plies of the same unidirectional (UD) carbon fiber prepreg Hexcel IM7/8552. The geometry and layup are presented in Table 1 . This cylinder is clamped on both ends using a sand-resin concrete and the final $R / t$ radius is about 510 .

2.1.3. Stainless Steel Cylindrical Shell "SST-1" with $R / t=500$. The stainless steel cylinder SST-1 is manufactured and tested at RTU. The cylinder is manufactured from a flat plate of AISI 304 stainless steel, rolled up to the desired curvature, and closed forming a top joint which is laser-welded. The 


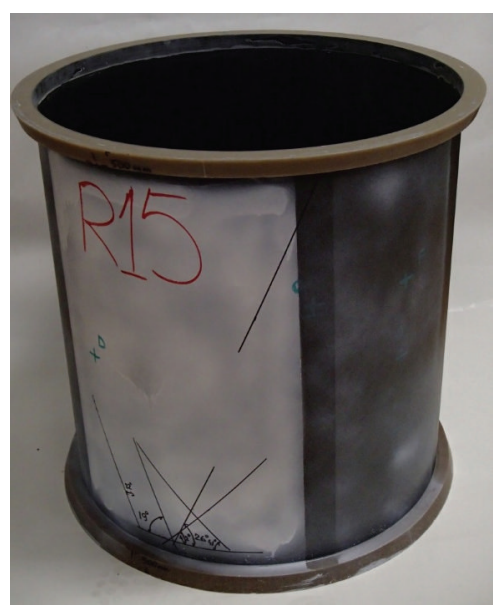

RTU-R15 cylinder

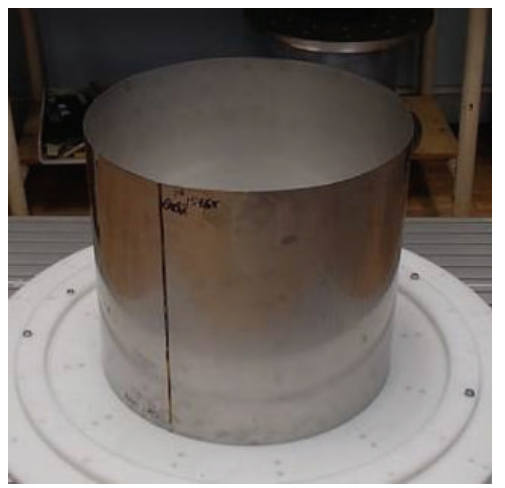

RTU-SST-1 cylinder (one welding line)

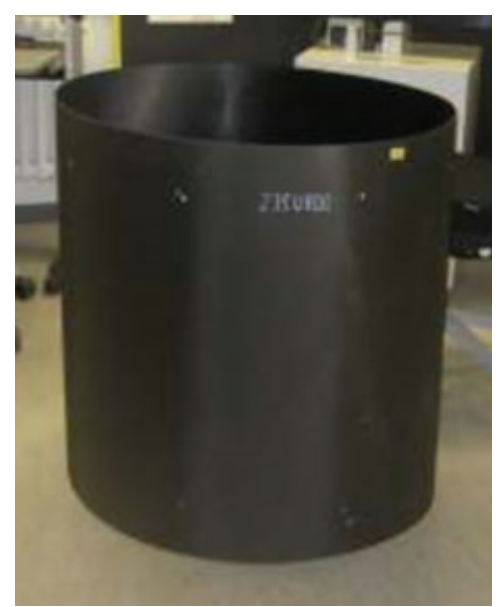

DLR-Z37 cylinder

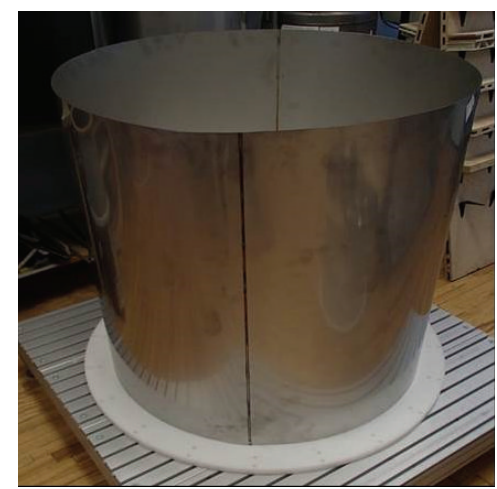

RTU-SST-2 cylinder (two welding lines)

FIGURE 1: Overview of tested cylindrical shells.

geometric parameters are presented in Table 1 . The material properties are detailed in Table 3 , where $S_{Y}$ is the yield strength and $S_{U}$ is the ultimate strength.

The laser welding technique used to join both ends of the specimen generates a characteristic imperfection signature, not observed on the composite specimens, which is discussed in the next sections.

After fabrication, the top and bottom edges are clamped using a resin potting supported by metallic rings.

2.1.4. Stainless Steel Cylindrical Shell "SST-2" with $R / t=800$. The stainless steel cylinder SST-2 is also manufactured and tested at RTU. The cylinder is manufactured from two flat plates of the same AISI 304 stainless steel material used on SST-1, rolled up to the desired curvature, and closed using laser welding between the ends. In this case, each plate is half of the cylinder's perimeter long, resulting in a symmetrical imperfection signature due to the two welding lines. The geometric parameters are presented in Table 1.

Figure 1 shows a general view of each tested specimen.

2.2. Characterization of Initial Geometric Imperfection. A laser scan (Panasonic HL-G1 sensor) is used to measure the geometric imperfection on the inner surface of R15, SST1 , and SST-2 cylinders at RTU. The laser scan is controlled
TABLE 2: Measured material properties of UD prepreg Hexcel IM7/8552.

\begin{tabular}{lccc}
\hline & Mean value & & Std. deviation [\%] \\
\hline$E_{1}{ }^{T}$ & 171.5 & $\mathrm{GPa}$ & 2.6 \\
$E_{1}{ }^{\mathrm{C}}$ & 150.2 & $\mathrm{GPa}$ & 4.6 \\
$E_{2}{ }^{T}$ & 8.9 & $\mathrm{GPa}$ & 4.2 \\
$E_{2}{ }^{\mathrm{C}}$ & 9.4 & $\mathrm{GPa}$ & 10.9 \\
$G_{12}$ & 5.1 & $\mathrm{GPa}$ & 7.8 \\
$v_{12}$ & 0.32 & & 13 \\
$S_{1}{ }^{T}$ & 2300 & $\mathrm{MPa}$ & 13.8 \\
$S_{1}{ }^{\mathrm{C}}$ & 857 & $\mathrm{MPa}$ & 10.1 \\
$S_{2}{ }^{T}$ & 40 & $\mathrm{MPa}$ & 20.4 \\
$S_{2}{ }^{C}$ & 203 & $\mathrm{MPa}$ & 3.9 \\
$S_{12}$ & 51 & $\mathrm{MPa}$ & 8.4 \\
$t$-ply & 0.125 & $\mathrm{~mm}$ & \\
\hline
\end{tabular}

using an in-house software and the acquired data is exported in real time to a plain text file for further analysis and postprocessing.

For Z37 cylinder DLR uses ATOS 3D measurement system in order to characterize the initial geometric imperfections from the outer surface. 


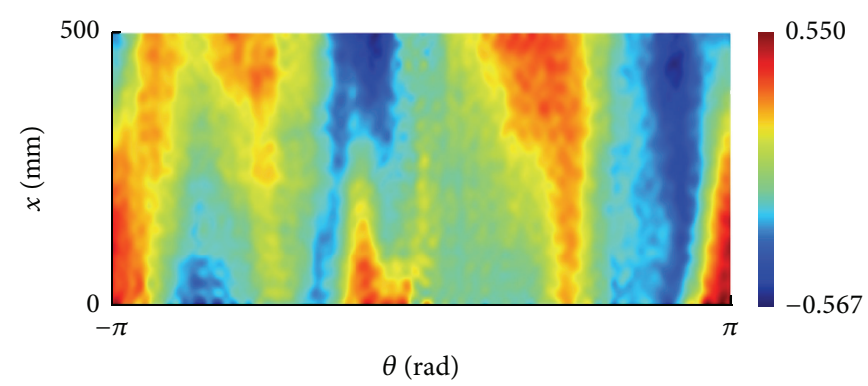

RTU-R15 initial geometric imperfection measured on the inner surface $(\mathrm{mm})$

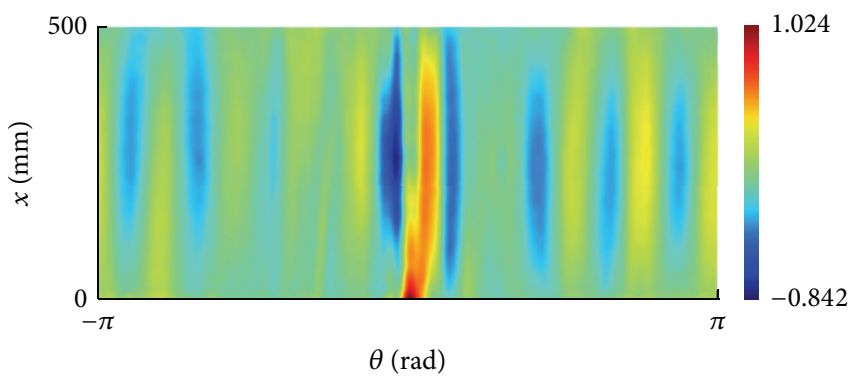

RTU-SST-1 initial geometric imperfection measured on the inner surface $(\mathrm{mm})$
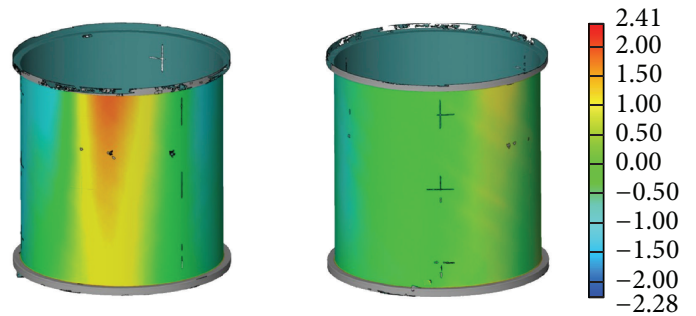

DLR-Z37 initial geometric imperfection measured on the outer surface $(\mathrm{mm})$

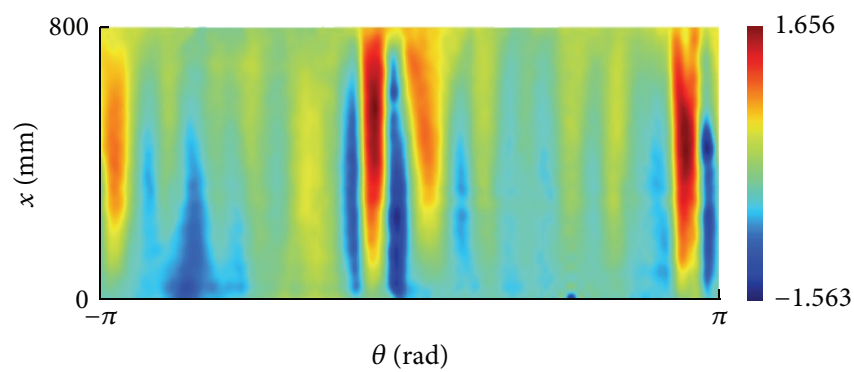

RTU-SST-2 initial geometric imperfection measured on the inner surface $(\mathrm{mm})$

FIGURE 2: Initial geometric imperfection on the studied cylinders.

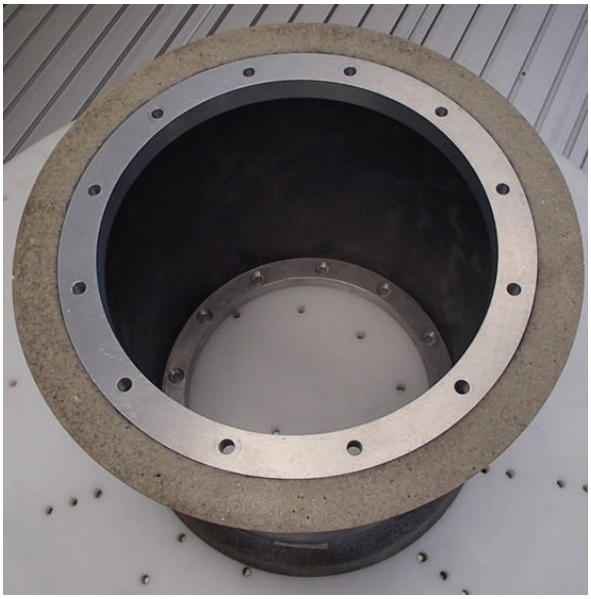

Figure 3: Boundary conditions on top and bottom edges.

For all cases the best-fit-cylinder algorithm is applied afterwards over the raw data to eliminate the rigid body motion modes from the measurements. The results are presented in Figure 2, where the imperfection pattern generated by the welding process on SST- 1 and SST- 2 cylinders can be seen.

\subsection{Experimental Test Setup and Boundary Conditions.} Because the tests are performed using different testing machines and laboratories (RTU and DLR facilities), the boundary conditions and test setups vary between the studied cases, allowing the authors to verify the robustness of
TABLE 3: Material properties of AISI 304 stainless steel.

\begin{tabular}{lcc}
\hline$E$ & 193 & $\mathrm{GPa}$ \\
$G$ & 77 & $\mathrm{GPa}$ \\
$v$ & 0.29 & \\
$S_{Y}$ & 215 & $\mathrm{MPa}$ \\
$S_{U}$ & 505 & $\mathrm{MPa}$ \\
\hline
\end{tabular}

the proposed VCT approach. In general, the top and bottom cylinder edges are clamped for all cases using a resin potting that is $25 \mathrm{~mm}$ height for RTU and $20 \mathrm{~mm}$ for DLR cylinders, together with metallic rings placed at the inner face, as presented in Figure 3. For testing, each cylinder is placed between two metallic plates and glued with epoxy resin. For R15, SST-1, and SST-2 a spherical joint is placed between the crosshead of the testing machine and the loading plate, in order to avoid bending moments (see Figures 4 and 5). DLR test setup for Z37 cylinder uses special loading tables that can be adjusted in order to avoid loading imperfection and bending introduction along the cylinder edges (see Figure 6).

The compression tests for R15 and SST-1 cylindrical shells are performed using a Zwick $100 \mathrm{kN}$ testing machine. Because SST-2 is too large to be fitted on the same machine, an Instron SATEC $600 \mathrm{kN}$ testing machine is used in this case. Z37 cylinder is tested at DLR, using its own hydraulic testing machine. In all cases the compressive load is measured using a load cell and it is applied using displacement control at a constant velocity of $0.5 \mathrm{~mm} / \mathrm{min}$. 


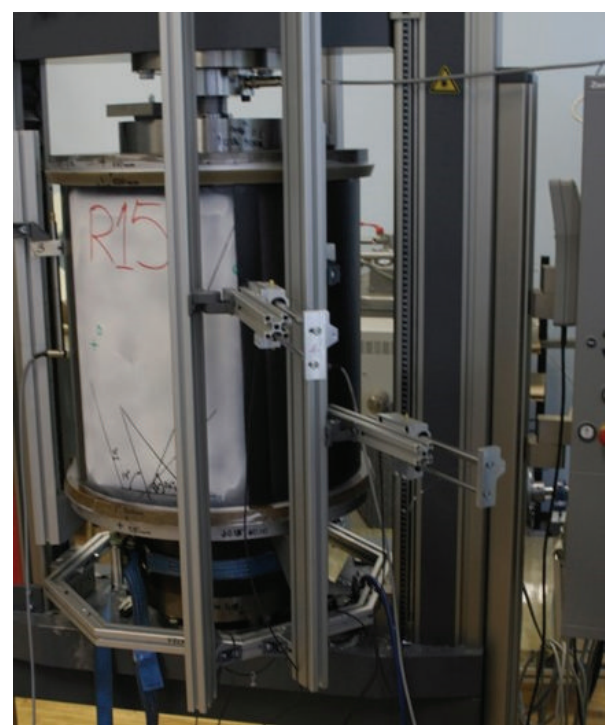

FIGURE 4: Experimental test setup for compressive loading on R15 and SST-1 cylindrical shells (RTU).

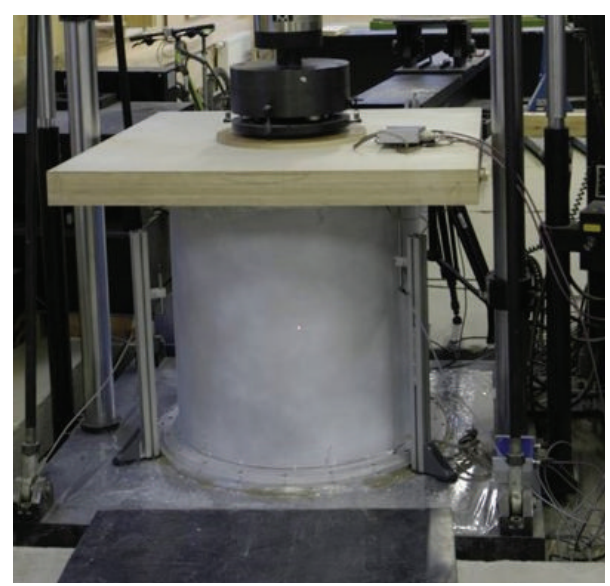

FIGURE 5: Experimental test setup for compressive loading on SST-2 cylindrical shell (RTU).

For the composite cylindrical shells R15 and Z37 two types of tests are carried out in order to verify the proposed VCT approach. First, the cylinder is loaded in compression up to buckling. Notice that the cylinders are designed to buckle in the elastic regime in order to minimize accumulated damage during repeated tests. Once the onset of buckling is found, a second test is performed using a Polytec laser vibrometer to characterize the first natural frequency of vibration and mode shape for different values of applied compressive load, below the onset of buckling. For this test, the cylinder surface is excited with a periodic chirp signal using a loudspeaker placed perpendicularly to the cylinder's surface and the laser is positioned in a rectangular grid of points in order to map the vibration mode for the whole signal spectrum.

The stainless steel cylinders SST-1 and SST-2 must be tested following a different approach. Since the buckling event will produce plastic deformation, no further test can be

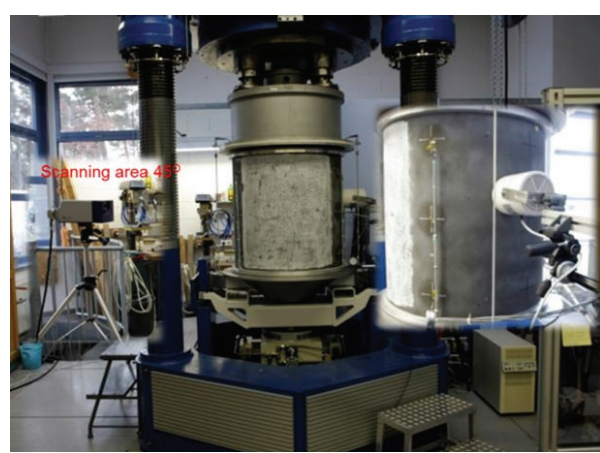

FIGURE 6: Experimental test setup for compressive loading on Z37 cylindrical shell (DLR).

TABLE 4: Experimental buckling load of tested cylinders.

\begin{tabular}{lc}
\hline Cylinder & Experimental buckling load $[\mathrm{kN}]$ \\
\hline R15 & 24.2 \\
Z37 & 59.0 \\
SST-1 & 70.2 \\
SST-2 & 49.9 \\
\hline
\end{tabular}

carried out once the onset of buckling is reached. For these cases the compressive load is applied in small increments and the frequencies and vibration modes are measured using the laser vibrometer. This procedure is followed up to buckling, when the structure collapses and is no longer useful.

2.4. Experimental Results. The buckling load obtained for each tested cylinder is summarized in Table 4.

The variation of the first natural frequency of vibration measured on each cylinder is presented in Table 5. Additionally, for the SST-2 cylinder, the second vibration mode is measured (see Table 6) in order to compare the predicted buckling load with the one obtained using the variation of the first vibration mode. An example of the vibration mode shape obtained from the laser vibrometer and overlaid on top of the test specimen Z37 is shown in Figure 7.

\section{Validation of the Proposed VCT Approach}

In order to predict the onset of buckling following the proposed VCT approach, first presented by Arbelo et al. [15], one needs to know the evolution of the first vibration mode with a growing axial compression on the prebuckling regime, as presented in the previous section, and the critical buckling load of the perfect cylinder $\left(P_{\mathrm{cr}}\right)$. The latter can be obtained through a linear eigenvalue analysis of a simple finite element model.

For the present study, the finite element model (FEM) is generated using Abaqus. For all four cylinders the mesh adopted after the convergence analysis uses 160 S8R5 [20] square elements distributed along the circumference. The critical buckling loads obtained for a perfect cylindrical shell with the layup, dimensions, materials properties, and 
TABLE 5: Variation of the 1st vibration frequency with the applied load.

\begin{tabular}{|c|c|c|c|c|c|c|c|}
\hline \multicolumn{2}{|c|}{ R15 cylinder } & \multicolumn{2}{|c|}{ Z37 cylinder } & \multicolumn{2}{|c|}{ SST-1 cylinder } & \multicolumn{2}{|c|}{ SST- 2 cylinder } \\
\hline $\begin{array}{l}\text { Compressive } \\
\text { load }[\mathrm{kN}]\end{array}$ & $\begin{array}{c}\text { 1st vibration } \\
\text { mode }[\mathrm{Hz}]\end{array}$ & $\begin{array}{c}\text { Compressive } \\
\text { load }[\mathrm{kN}]\end{array}$ & $\begin{array}{c}\text { 1st vibration } \\
\text { mode }[\mathrm{Hz}]\end{array}$ & $\begin{array}{c}\text { Compressive } \\
\text { load }[\mathrm{kN}]\end{array}$ & $\begin{array}{c}\text { 1st vibration } \\
\text { mode }[\mathrm{Hz}]\end{array}$ & $\begin{array}{c}\text { Compressive } \\
\text { load }[\mathrm{kN}]\end{array}$ & $\begin{array}{c}\text { 1st vibration } \\
\text { mode }[\mathrm{Hz}]\end{array}$ \\
\hline 0.09 & 216.75 & 0 & 152.5 & 0 & 232.75 & 0 & 117.5 \\
\hline 2.18 & 212.25 & 1.2 & 151.5 & 4.94 & 231.75 & 5.2 & 116.5 \\
\hline 4.16 & 208 & 10.2 & 148.75 & 10.02 & 230.5 & 10.22 & 115.25 \\
\hline 6.16 & 203.5 & 20.2 & 143 & 20.05 & 226.5 & 15.24 & 113.75 \\
\hline 8.2 & 198.75 & 30.2 & 137.25 & 30.1 & 222.5 & 20.24 & 112.5 \\
\hline 10.55 & 193.5 & 40.2 & 130.75 & 40.04 & 218.5 & 24.97 & 110 \\
\hline 12.77 & 188.25 & 50.2 & 123.25 & 50.2 & 213.5 & 30.24 & 109.75 \\
\hline 15 & 182.75 & 55.2 & 119 & 55.07 & 211 & 35.23 & 107.25 \\
\hline 17.57 & 175.5 & 58.2 & 115.5 & 60.25 & 208 & 40.22 & 106.5 \\
\hline 19.42 & 170 & & & & & 45.23 & 102.5 \\
\hline 20.63 & 166.25 & & & & & & \\
\hline 22.4 & 159.75 & & & & & & \\
\hline
\end{tabular}

TABLE 6: Variation of the 2nd vibration frequency with the applied load on the SST-2 cylinder.

\begin{tabular}{lc}
\hline \multicolumn{2}{c}{ SST-2 cylinder } \\
Compressive load $[\mathrm{kN}]$ & 1st vibration mode $[\mathrm{Hz}]$ \\
\hline 0 & 122 \\
5.2 & 121.25 \\
10.22 & 120.25 \\
15.24 & 119.25 \\
20.24 & 118.25 \\
24.97 & 117 \\
30.24 & 114.75 \\
35.23 & 113.25 \\
40.22 & 112.25 \\
45.23 & 109.75 \\
\hline
\end{tabular}

TABLE 7: Critical buckling load of tested cylinders.

\begin{tabular}{lc}
\hline Cylinder & Critical buckling load $[\mathrm{kN}]$ \\
\hline R15 & 35.1 \\
Z37 & 89.8 \\
SST-1 & 183.1 \\
SST-2 & 183.1 \\
\hline
\end{tabular}

boundary conditions used on the studied cases are summarized in Table 7.

The proposed VCT approach can be plotted in function of the dimensionless parameters $(1-p)^{2}$ versus $\left(1-f^{2}\right)$, as shown in Figure 8, for each study case.

The minimum value of $(1-p)^{2}$ obtained using this approximation represents the square of the drop of the load carrying capacity $\left(\xi^{2}\right)$. Using (1), the predicted buckling load obtained from the proposed VCT approach for each case is presented in Table 8. A very good correlation can be noticed with the experimental buckling load measured during testing
TABLE 8: Buckling load prediction using the VCT approach for the different studied cases.

\begin{tabular}{lcc}
\hline Cylinder & $\begin{array}{c}\text { Predicted buckling load } \\
\text { using VCT }[\mathrm{kN}]\end{array}$ & $\begin{array}{c}\text { Deviation from } \\
\text { experimental results [\%] }\end{array}$ \\
\hline R15 & 26.62 & 10 \\
Z37 & 58.41 & 1 \\
SST-1 & 70.2 & 0 \\
SST-2 & 52.5 & 5 \\
\hline
\end{tabular}

(see Table 4), with less than $10 \%$ of deviation (in most of the studied cases the deviation is lower than 5\%).

Additional studies are carried out for the SST-2 structure, where the proposed VCT approach is applied using the second vibration mode. The predicted buckling load in this case is $47.96 \mathrm{kN}$, with a deviation of $3.9 \%$ from the experimental results. It must be mentioned that this result correlates better than the original approach, where the first vibration mode is used (see Table 8). Another important observation is that using the second vibration mode makes the proposed VCT approach more conservative.

The predicted buckling load for R15 cylinder presents a fairly good correlation, despite being clearly not as good as the other studied cases. The authors found out that the load around the top and bottom edges was not evenly distributed along the circumference during testing. In this way, the vibration analysis can give nonconservative results depending on the relative position of the laser scan and the measured surface region. Further studies are currently being conducted in order to quantify a relationship between the initial loading imperfection around the edges and the buckling loads predicted using the VCT.

Furthermore, it is interesting to investigate the minimum threshold of compressive load needed to achieve a good correlation with the proposed VCT approach, with less than $10 \%$ deviation from the experimental buckling load. 
TABLE 9: Buckling load prediction using the VCT approach for different loading ranges on Z37 cylinder.

\begin{tabular}{lcc}
\hline $\begin{array}{l}\text { Max. load used for VCT } \\
\text { [\% of experimental buckling load] }\end{array}$ & Predicted buckling load using VCT [kN] & $\begin{array}{c}\text { Deviation from experimental results } \\
{[\%]}\end{array}$ \\
\hline $98.6 \%$ & 58.41 & 1 \\
$93.6 \%$ & 56.58 & 4.1 \\
$85.1 \%$ & 53.19 & 9.8 \\
$68.1 \%$ & 45.35 & 23.1 (fail) \\
\hline
\end{tabular}

TABLE 10: Buckling load prediction using the VCT approach for different loading ranges on SST-1 cylinder.

\begin{tabular}{lcc}
\hline $\begin{array}{l}\text { Max. load used for VCT } \\
\text { [\% of experimental buckling load] }\end{array}$ & Predicted buckling load using VCT [kN] & $\begin{array}{c}\text { Deviation from experimental results } \\
{[\%]}\end{array}$ \\
\hline $85.8 \%$ & 70.22 & 0 \\
$78.4 \%$ & 67.11 & 4.4 \\
$71.5 \%$ & 63.34 & 9.8 \\
$57 \%$ & 53.74 & 23.4 (fail) \\
\hline
\end{tabular}

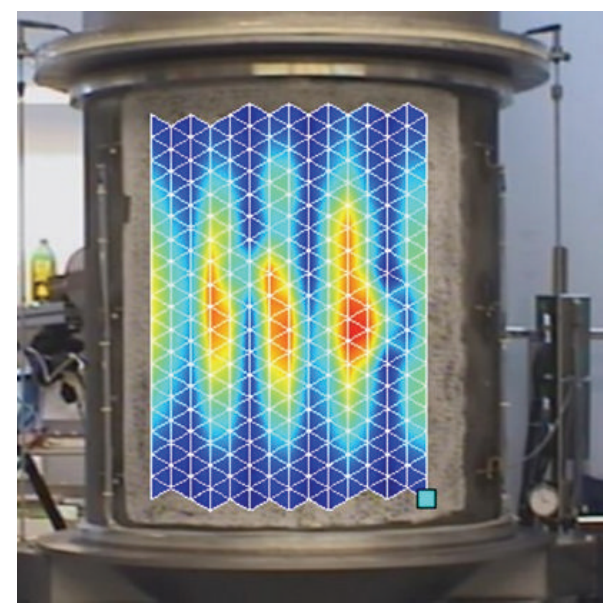

FIGURE 7: Fist vibration mode shape measured during testing (DLRZ37).

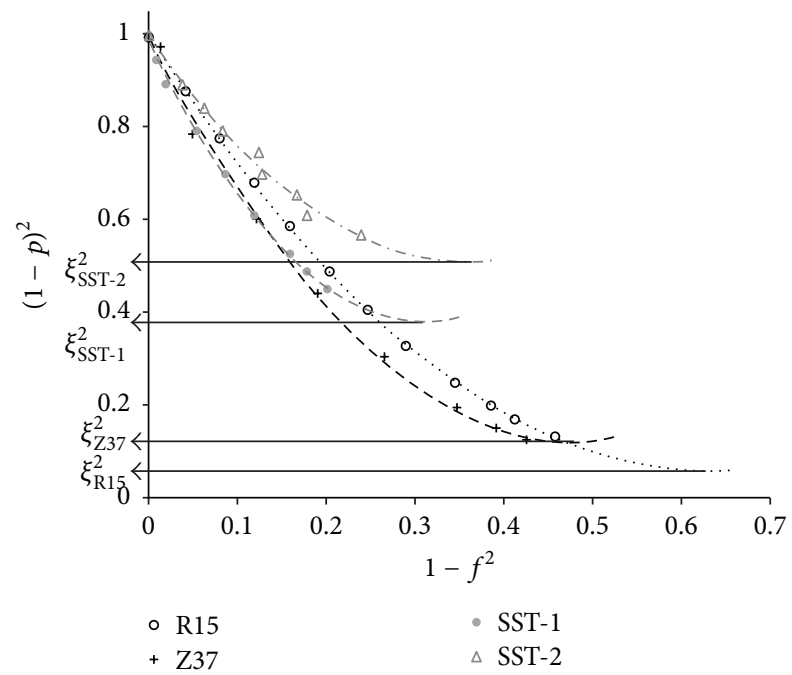

Figure 8: Plot of $(1-p)^{2}$ versus $\left(1-f^{2}\right)$ and 2nd-order fit for each tested cylinder.
Tables 9-11 present the VCT results obtained for Z37, SST1 , and SST-2 cylinders, using different ranges of applied load (always starting from the unloaded state).

It is clear that the correlation degrades when the maximum load is lower than $70 \%$ of the buckling load.

From these results one concludes that the present approach could be applied as an experimental nondestructive method to estimate the buckling load on unstiffened cylindrical shells loaded in compression. In addition, the authors recommend monitoring also the second vibration mode during the vibration tests, since a better correlation has been found for SST-2 cylinder using the second vibration mode. Further experimental investigations are being addressed by the authors in order to verify the proposed VCT approach for cylindrical shells with different levels of loading imperfections and initial geometric imperfections.

\section{Summary and Concluding Remarks}

In this paper a validation of a novel empirical approach using the vibration correlation technique as a nondestructive method to estimate the buckling load of unstiffened cylindrical shells is presented. Four tests are carried out in order to verify the robustness of the proposed approach for different structures under different test setups. The material properties and initial geometric imperfections are measured using state-of-the-art techniques. The variation of the first natural frequency of vibration with the applied compressive load on four cylindrical shells is measured up to buckling. The proposed approach presents a very good correlation when the maximum load adopted in the VCT is higher than $80 \%$ of the buckling load obtained with tests. If no failure occurs at this maximum load, the proposed approach characterizes a truly nondestructive methodology. Furthermore, it is observed that the use of the second vibration mode for the estimation of the buckling load can provide better predictions in some cases. Therefore, the authors recommend monitoring the evolution of the first and second vibration modes with the increase of the compressive load. 
TABLE 11: Buckling load prediction using the VCT approach for different loading ranges on SST-2 cylinder (second vibration mode).

\begin{tabular}{lcc}
\hline $\begin{array}{l}\text { Max. load used for VCT } \\
\text { [\% of experimental buckling load] }\end{array}$ & Predicted buckling load using VCT [kN] & Deviation from experimental results [\%] \\
\hline $90.6 \%$ & 47.96 & 3.9 \\
$80.6 \%$ & 42.77 & 14.3 (fail) \\
$70.6 \%$ & 36.38 & 27.1 (fail) \\
\hline
\end{tabular}

Further experimental investigations are being addressed by the authors in order to verify this new methodology for cylindrical shells with different levels of load imperfection and initial geometric imperfection. Additional experimental tests are currently under development to further validate the proposed approach for composite and metallic conical structures.

\section{Disclaimer}

The information in this paper reflects only the author's views and the European Community is not liable for any use that may be made of the information contained therein.

\section{Conflict of Interests}

The authors declare that there is no conflict of interests regarding the publication of this paper.

\section{Acknowledgments}

The research leading to these results has received funding from the European Community's Seventh Framework Programme (FP7/2007-2013), Grant Agreement no. 282522 (http://www.desicos.eu/).

\section{References}

[1] R. V. Southwell, "On the analysis of experimental observations in problems of elastic stability," Proceedings of the Royal Society of London A, vol. 135, pp. 601-616, 1932.

[2] G. D. Galletly and T. E. Reynolds, "A simple extension of Southwell's method for determining the elastic general instability pressure of ring stiffened cylinders subjected to external pressure," SESA Proceedings, vol. 12, no. 2, pp. 141-153, 1956.

[3] A. Sommerfeld, "Eine einfache Vorrichtung zur Veranschaulichung des Knickungsvorganges," in Zeitschrift des Verein Deutscher Ingenieure (ZVDI), pp. 1320-1323, 1905.

[4] T. H. Chu, Determination of buckling loads by frequency measurements [Ph.D. thesis], California Institute of Technology, Pasadena, Calif, USA, 1949.

[5] H. Lurie, "Lateral vibrations as related to structural stability," Journal of Applied Mechanics, vol. 19, pp. 195-204, 1952.

[6] J. H. Meier, "The determination of the critical load of a column or stiffened panel in compression by the vibration method," Proceedings of the Society for Experimental Stress Analysis, vol. 11, pp. 233-234, 1953.

[7] J. Singer, J. Arbocz, and T. Weller, Buckling Experiments, Experimental Methods in Buckling of Thin-Walled Structures, Volume 2, chapter 15, John Wiley \& Sons, New York, NY, USA, 2002.
[8] R. Degenhardt, A. Kling, A. Bethge et al., "Investigations on imperfection sensitivity and deduction of improved knockdown factors for unstiffened CFRP cylindrical shells," Composite Structures, vol. 92, no. 8, pp. 1939-1946, 2010.

[9] E. Skukis, K. Kalnins, and A. Chate, Preliminary Assessment of Correlation between Vibrations and Buckling Load of Stainless Steel Cylinders. Shell Structures Theory and Applications, CRC Press, London, UK, 2013.

[10] R. Zimmemann, "Buckling research for imperfection tolerant fiber composite structures," in Proceedings of the Conference on Spacecraft Structures, Materials and Mechanical Testing, Noordwijk, The Netherlands, March 1996.

[11] C. Hühne, R. Zimmermann, R. Rolfes, and B. Geier, "Sensitivities to geometrical and loading imperfections on buckling of composite cylindrical shells," in Proceedings of the European Conference on Spacecraft Structures, Materials and Mechanical Testing, pp. 11-13, Toulouse, France, December 2002.

[12] M. W. Hilburger, M. P. Nemeth, and J. H. Starnes Jr., "Shell buckling design criteria based on manufacturing imperfection signatures," NASA Report TM-2004-212659, NASA, 2004.

[13] R. Degenhardt, A. Bethge, A. King et al., "Probabilistic approach for improved buckling knock-down factors of CFRP cylindrical shells," in Proceedings of the 1st CEAS European Air and Space Conference, Berlin, Germany, September 2008.

[14] E. L. Jansen, H. Abramovich, and R. Rolfes, "The direct prediction of buckling loads of shells under axial compression using VCT-towards an upgraded approach," in Proceedings of the 27th Congress of the International Council of the Aeronautical Sciences, St. Petersburg, Russia, September 2014.

[15] M. A. Arbelo, S. F. M. de Almeida, M. V. Donadon et al., "Vibration correlation technique for the estimation of real boundary conditions and buckling load of unstiffened plates and cylindrical shells," Thin-Walled Structures, vol. 79, pp. 119128, 2014.

[16] M. A. Souza, W. C. Fok, and A. C. Walker, "Review of experimental techniques for thin-walled structures liable to buckling, part I-neutral and unstable buckling," Experimental Techniques, vol. 7, no. 9, pp. 21-25, 1983.

[17] American Society for Testing and Materials, ASTM D3039/D3039M-08. Standard Test Method for Tensile Properties of Polymer Matrix Composite Materials, American Society for Testing and Materials, West Conshohocken, Pa, USA, 2011.

[18] ASTM, "Standard test method for compressive properties of polymer matrix composite materials with unsupported gage section by shear loading," ASTM D3410/D3410M-03, American Society for Testing and Materials, Philadelphia, Pa, USA, 2011.

[19] American Society for Testing and Materials, ASTM D3518/D3518M-94. Standard Test Method for In-Plane Shear Response of Polymer Matrix Composite Materials by Tensile Test of a $\pm 45^{\circ}$ Laminate, American Society for Testing and Materials, West Conshohocken, Pa, USA, 2011.

[20] ABAQUS User's Manual, Abaqus Analysis User's Manual, 2011. 

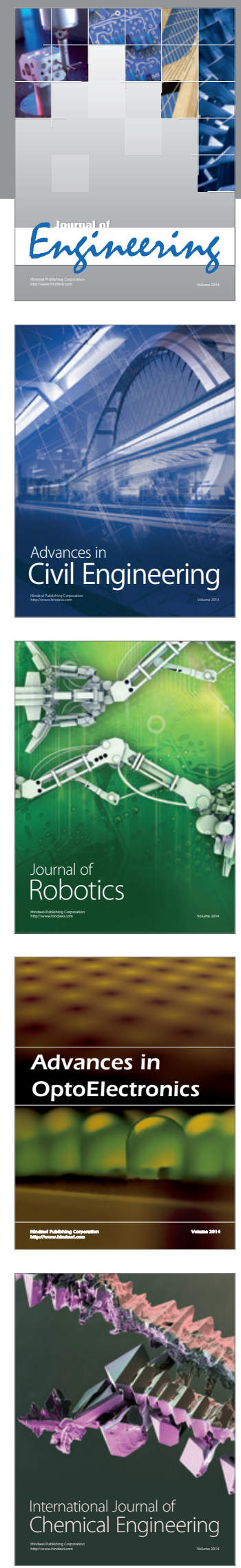

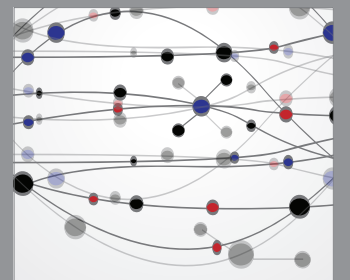

The Scientific World Journal
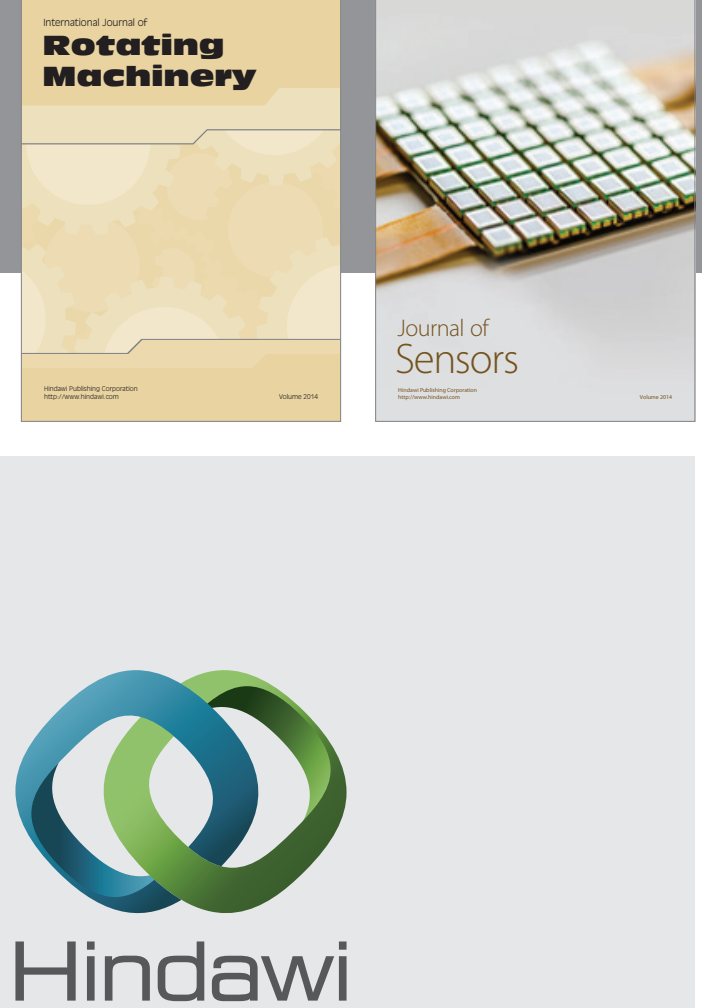

Submit your manuscripts at http://www.hindawi.com
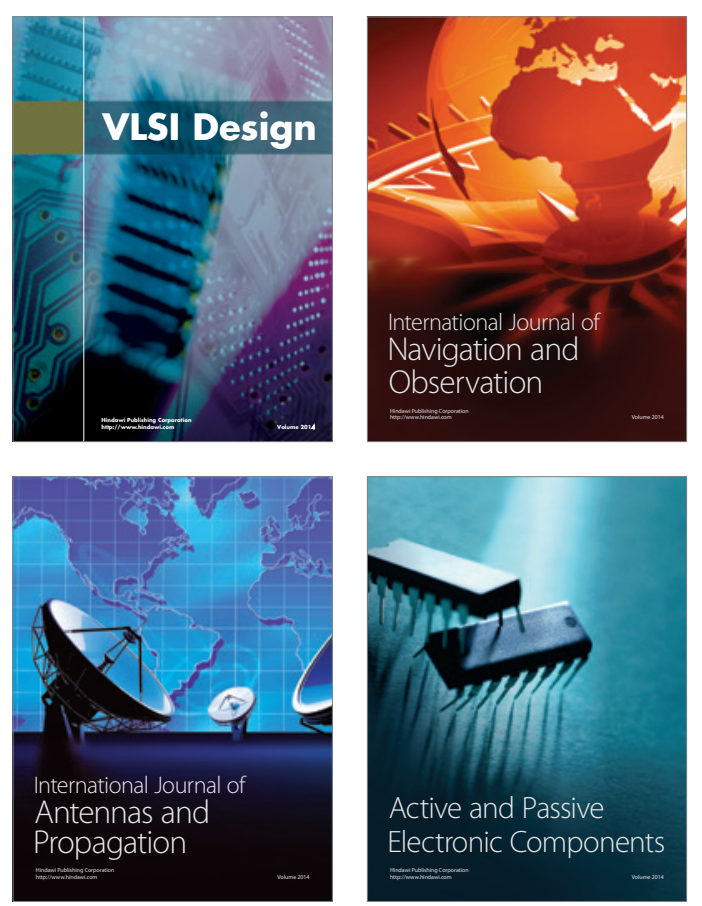
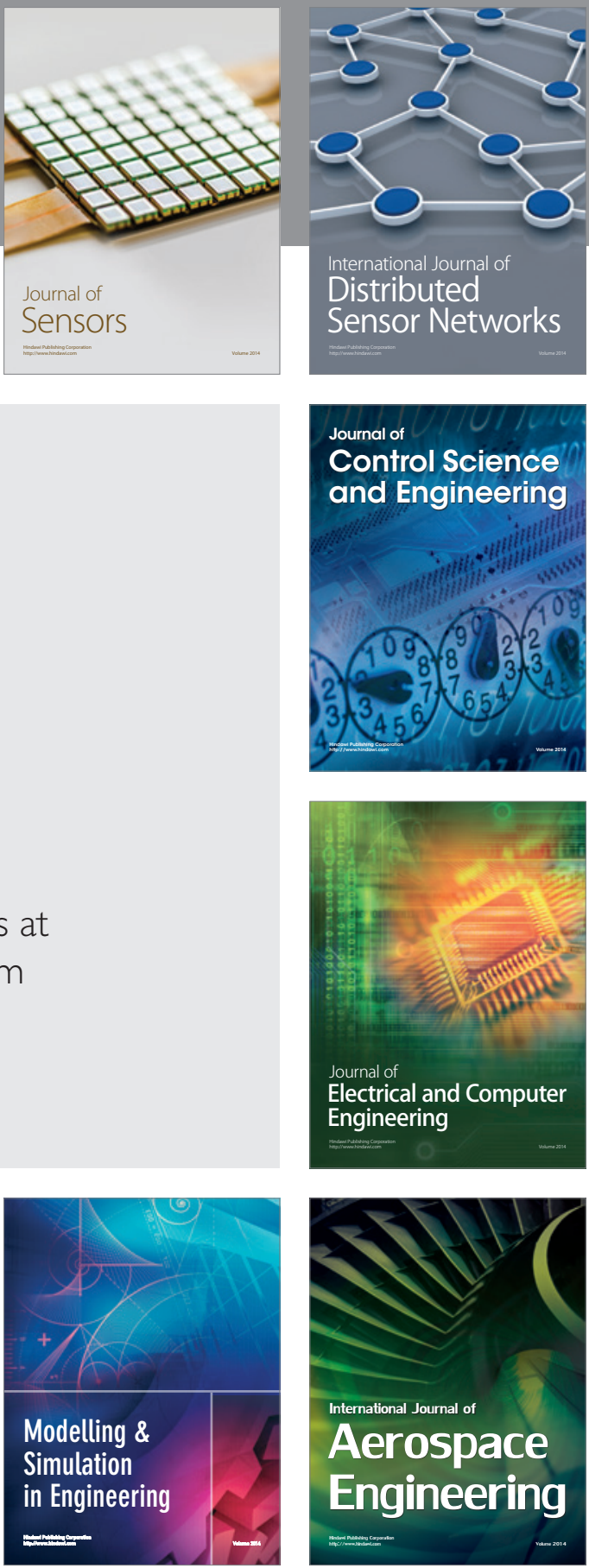

Journal of

Control Science

and Engineering
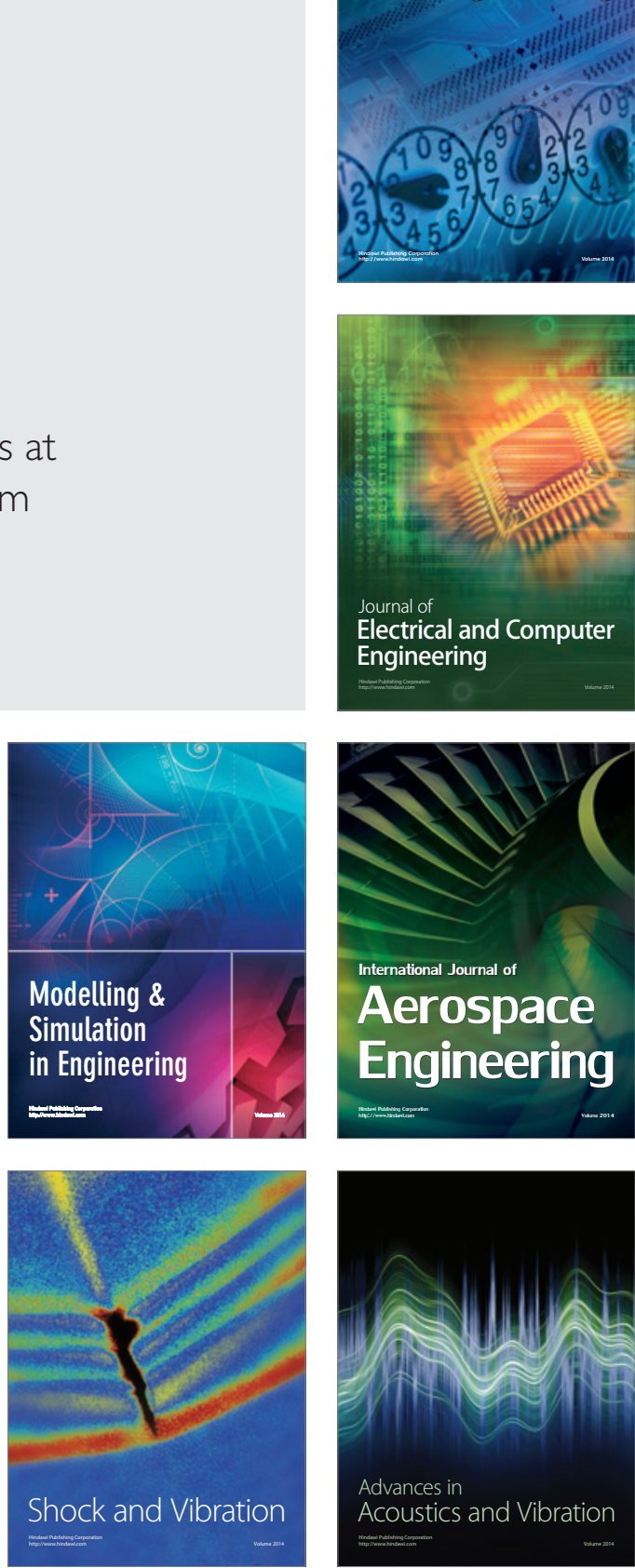